\title{
Comparison of radiogrammetrical metacarpal indices in children and reference data from the First Zurich Longitudinal Study
}

\author{
David D. Martin • Conrad Heckmann • Julia Neuhof • \\ Oskar G. Jenni • Michael B. Ranke • Gerhard Binder
}

Received: 25 May 2011 /Revised: 17 December 2011 / Accepted: 16 January 2012 / Published online: 6 June 2012

(C) The Author(s) 2012. This article is published with open access at Springerlink.com

\begin{abstract}
Background A number of radiogrammetrical metacarpal indices are in use, some of which have been adapted for children.

Objective The purpose of this study was to compare four known indices - bone mineral density (BMD), relative cortical area, Exton-Smith index, bending breaking resistance index - and the more recently defined pediatric bone index (PBI) according to the two criteria of minimum height dependence and minimum variability in children of equal bone age.

Materials and methods A total of 3,121 left-hand radiographs from 231 healthy Caucasian children ranging in age from 3 to 19 years old were analysed using BoneXpert ${ }^{\circledR}$, a programme for automatic analysis of hand radiographs and assessment of bone age.

Results Dependence on height for chronological age or bone age and the mean relative standard deviation were lowest in the PBI for both genders pooled. The differences in height dependence were statistically significant and are shown to be clinically relevant. Reference data for PBI are presented.
\end{abstract}

D. D. Martin $(\bowtie) \cdot$ C. Heckmann $\cdot$ J. Neuhof $\cdot$ M. B. Ranke

G. Binder

Pediatric Endocrinology and Diabetology,

University Children's Hospital Tübingen,

Hoppe-Seyler-Str. 1,

72076 Tuebingen, Germany

e-mail: david.martin@med.uni-tuebingen.de

O. G. Jenni

Child Development Centre, University Children's Hospital,

Steinwiesstrasse 75 ,

8032 Zurich, Switzerland
Conclusion PBI may be a better indicator than BMD for bone health in children; however, verification in a clinical group is needed.

Keywords Radiogrammetry · Densitometry $\cdot$ Metacarpal dimensions $\cdot$ Skeletal growth $\cdot$ Child $\cdot$ Reference values

\section{Introduction}

Bone densitometry is increasingly used for following the course of various paediatric disorders and treatments [1-9]. While still largely the domain of dual-energy X-ray densitometry (DXA) and peripheral quantitative CT (pQCT), with the advance of computerised image analysis over the past decade the field has again become accessible for radiogrammetrical techniques. These have the advantages of being inexpensive and convenient to use in children as well as involving lower radiation exposure $[4,10]$ and involve lower radiation exposure than both DXA and pQCT [11]. Methods that perform bone age assessment and radiogrammetrical measurements in a single run, like the one presented in this paper, pose a further advantage of the radiogrammetrical option. Since bone densitometry measurements are more dependent on skeletal maturity than on chronological age, a bone age-estimate should accompany any densitometry measurement in children suspected of having a developmental disorder [12]. Moreover, radiographs are readily available for retrospective radiogrammetrical studies. The precision of radiogrammetry is as good as or better than that of absorptiometrical techniques [7, 13-16]. It is based on the simplifying assumption that the density of cortical bone is constant and that cortical mass and volume are therefore interchangeable measurements. This assumption is valid in all but a few rare clinical conditions. The relative merits of radiogrammetry, DXA and pQCT are 
further discussed by Thodberg at al. [11]. Radio grammetrical measures are generally based on metacarpal width (W), length (L) and cortical thickness (T) and the derived measurement of medullary diameter, $\mathrm{M}=\mathrm{W}-2 \cdot \mathrm{T}$.

The primary concern of bone densitometry is bone strength. Bone mass has been shown to account for 75$85 \%$ of the variance in the ultimate strength [17, 18]. An obvious point of departure in designing a radiogrammetrical index for long bones therefore is the cross-sectional area $\mathrm{A}=$ $\pi(\mathrm{W} / 2)^{2}-\pi((\mathrm{W} / 2)-\mathrm{T})^{2}=\pi \mathrm{T} \cdot \mathrm{W}(1-\mathrm{T} / \mathrm{W})$. To date the most widely used radiogrammetrical index has been area bone mineral density (BMD), which is defined as the cortical volume of a metacarpal bone divided by the area onto which it projects in the frontal view: $\pi \cdot \mathrm{T} \cdot(1-\mathrm{T} / \mathrm{W})=\mathrm{A} / \mathrm{W}$ and is therefore measured in units of length [mm] $[4,5,8,9,13$, $15,19-24]$. BMD is often also referred to as DXR-BMD to distinguish it from area bone mineral density measured by DXA (DXA-BMD), which is measured in unit $\mathrm{g} / \mathrm{cm}^{2}$. These two measurements in turn must be distinguished from volumetric bone mineral density as measured by pQCT, which is given in units of true density, i.e. $\mathrm{g} / \mathrm{cm}^{3}$. Another radiogrammetrical index is the dimensionless relative cortical area (RCA, defined here as $\left.\left(\mathrm{W}^{2}-\mathrm{M}^{2}\right) / \mathrm{W}^{2}\right) * 10 \approx \mathrm{A} / \mathrm{W}^{2}$ ) [25-27], which is approximately proportional to the well-known metacarpal index, $\mathrm{MCI}=2 \cdot \mathrm{T} / \mathrm{W}$. It was decided to examine the RCA rather than the MCI because it is more readily comparable with other indices derived from A. In contrast, the bending breaking resistance index (BBRI) was formulated to give the fracture resistance of an idealised long bone of perfectly cylindrical shape to bending under simplifying assumptions: $\left(\mathrm{W}^{4}-\mathrm{M}^{4}\right) /(\mathrm{W} \cdot 100) \approx \mathrm{A} \cdot\left(\left(\mathrm{W}^{2}+\mathrm{M}^{2}\right) / \mathrm{W}\right)\left[\mathrm{mm}^{3}\right]$ [28]. The BBRI is thus a special case of the section modulus known from engineering mechanics, which has also been used by other authors to describe the structural-as opposed to material-properties that co-determine bone strength [29, 30]. However an index that is to reflect bone strength relative to the bone strength requirements of an individual should as far as possible abstract from differences in body size, which neither the BMD or the BBRI does [13, 31, 32]. This was attempted with Exton-Smith's dimensionless index, $\mathrm{ESI}=100 \cdot \mathrm{T}(1-\mathrm{T} / \mathrm{W}) / \mathrm{L} \approx \mathrm{A} /(\mathrm{W} \cdot \mathrm{L})[33,34]$. Recently a further index has been presented in an attempt to improve on BMD, RCA and ESI. It is called the paediatric bone index, $\mathrm{PBI}=10 \cdot \mathrm{T}$ $(1-\mathrm{T} / \mathrm{W}) /\left(\mathrm{W}^{0.33} \cdot \mathrm{L}^{0.33}\right) \approx \mathrm{A} /\left(\mathrm{W}^{1.33} \cdot \mathrm{L}^{0.33}\right)$ and is measured in $\mu \mathrm{m}^{0.33}$ [11]. It has been chosen for its low relative variability as compared with BMD, RCA and ESI in healthy Danish and Dutch children of equal bone age. This criterion is based on the assumption that, by virtue of nature's economy, an index that reflects the ideal bone geometry in terms of strength and material efficiency should cluster more closely around the biological optimum than any other.

Our aim was to replicate the relative variability analysis mentioned above on a new database. We further wanted to extend the comparison by examining the degree to which the indices under study compensate for differences in body size. For simplicity we assumed that compensation for body size is best achieved by an index whose height dependence in children of equal age or bone age is exactly zero. This is made plausible by the fact that height is one of the two strongest determinants of bone mass [31], while, at least within its normal range of variation, it is most probably not a major determinant of bone health.

Having established by reasoning that bone strength alone is not a suitable indicator for bone health, we were interested to know how far the criterion of height independence takes us away from that of bone strength. For this purpose we looked at correlations of the BBRI with the other four indices under study. It should be stressed that this was done with descriptive intent only. We assumed that the degree of correlation with bone strength, a requirement of an ideal bone health index, is unknown and therefore cannot serve as a criterion for finding such an index.

This paper is based on data from the First Zurich Longitudinal Study (1ZLS), comprising 3,121 left-hand radiographs from 231 healthy Caucasian children ages 3 years to 19 years old. The 1ZLS has led to several publications [35-40] in which the children and the study methods have been extensively described. These children, born around 1955, grew up in a time when obesity and the trend towards sedentary activities in children did not skew normative data. The 1ZLS is to our knowledge the largest BA-related database ever used for generating normative metacarpal data. Those for T, W, M and $\mathrm{L}$ have been published elsewhere [40].

\section{Materials and methods}

Informed consent was obtained from participants and parents who were present during the time of examination. The ethics committee of the University Children's Hospital Zurich confirmed that the study was performed according to the Declaration of Helsinki and conforms to legal and ethical norms.

\section{Data}

From a database comprising 3,379 left-hand radiographs from the 1ZLS, we selected 3,121 radiographs (1,661 from boys, 1,460 from girls) from 231 healthy Caucasian children (119 boys, 112 girls) by the following exclusion criteria: radiographs from children with bone age $<3.0$ years $(n=3)$ or girls with chronological age $>18.5$ years $(n=145)$ or boys with chronological age $>19.5$ years $(n=94)$ or poor radiograph quality $(n=16)$. The three radiographs excluded due to bone age $<3.0$ years, the only ones left in this bone age- 
range after removal of decayed film material, were excluded for statistical reasons. Bin sizes up to 6 years' chronological age were also reduced due to decay of some films. The 239 radiographs from the oldest boys and girls were excluded because in this age range the 1ZLS only covered subjects who were still growing, so these would on average be skeletally delayed. The 16 radiographs excluded for quality reasons were found by screening longitudinal charts for outliers [40]. The children of the 1ZLS were born between January 1954 and February 1956 and were selected randomly within the first 2 weeks after birth [35, 36]. Girls and boys were followed until the age of 18 years and 19 years, respectively, and beyond this until their height gain was less than $0.5 \mathrm{~cm}$ per 2 years. Ninety-four percent of the radiographs were taken within 2 weeks of the child's birthday and $99 \%$ within one month thereof. Data were classified by gender and chronological age, bone age or height interval. This gave 33 bins of chronological age-related and 33 bins of bone age-related data (range 3-18 years for girls and 319 years for boys in either case). Height-related data were only considered for children in the height-range 100 $160 \mathrm{~cm}$, giving 1,978 radiographs split into 24 bins (12 five-cm intervals for both genders). Due to the cut-off age, our bone age-related data are subject to a bias towards early maturers at the upper end, as explained in a study on the development of T, W, M and $\mathrm{L}$ in the same population [40]. This would affect bins 18-19 in boys and 17-18 in girls. Data outside the intended bone age-ranges of the software ( $>17$ years in boys and $>15$ years in girls) should not be used for reference purposes anyway. These biased data were included in the study, since they may reveal interesting characteristics of early maturers. This was found to have no influence on the outcome of the present comparison of metacarpal indices. Figure 1 shows the exclusion criteria applied to obtain the final data sets and subsets.

\section{Equipment}

The bone age and the T, W and $\mathrm{L}$ measurements for this study (Fig. 2) were automatically calculated by BoneXpert ${ }^{\circledR}$, a commercially available radiograph analysis software package (Visiana, Holte, Denmark). The hardware and radiograph quality requirements of the software, its method of image processing, and the system's compatibility with present-day clinical environments have previously been described [40]. The bone age-rating function has been validated in healthy and clinically relevant populations [38, 39, 41-44], and the method of determining $\mathrm{T}, \mathrm{W}$ and $\mathrm{L}$ has been described elsewhere [40].

\section{Precision}

The precision of the BA rating and radiogrammetrical functions have previously been demonstrated [37, 40]. The radiogrammetrical precision error is conventionally quoted as the precision of a single measurement, which in this case is the root mean square error (RMSE) divided by $\sqrt{ } 2$. Using the above-quoted precision calculation method this yielded $0.13 \mathrm{~mm}^{0.33}(2.5 \%)$ for PBI, $0.10 \mathrm{~mm}(2.8 \%)$ for BMD, $0.19(2.9 \%)$ for ESI, 0.15 $(2.3 \%)$ for RCA, and $0.16 \mathrm{~mm}^{3}(5.5 \%)$ for BBRI. These precision values were taken into account in calculating the variability of each index. The differences were small enough to have no effect on the indices' variability ranking. The PBI discussed in this paper is implemented in BoneXpert ${ }^{\circledR}$ under the name Bone Health Index (BHI). Its measurement unit is $\mu \mathrm{m}^{0.33}$, resulting in PBI values between 3 and 7 .

\section{Statistical analyses}

Statistical analyses were performed using the JMP 7 software package of SAS (JMP, Version 9, SAS Institute Inc., Cary, NC, USA, 2010). T, W and L were computed from their mean values in metacarpals $2-4, \mathrm{M}$ as $\mathrm{W}-2 \cdot \mathrm{T}$, and the mean and standard deviation of each measure was calculated for each gender by bone age-bin. The correlations of indices with bone strength were computed as Pearson correlation coefficient with the BBRI. The height-related bias of each index was determined in terms of the slope of the line of fit between the bone age-related and chronological age-related standard deviation scores (SDS) for height and the relevant index (CASDS and BASDS ratios) and expressed as SDS scores per 2 SDS of height. We used $99.8 \%$-confidence intervals $(\mathrm{CI})$ for the height-related bias of each bin to allow for 20 comparisons at significance level $\alpha=0.05$. The means and relative standard deviations of each index were calculated by gender and bone age-bin. The relative standard deviations were averaged over bone age bins 4 through 17 for girls and 4 through 18 for boys, and the resulting mean relative standard deviations were given with their ranges and standard deviations to reflect the scatter of each index. The 95\%-CI was calculated for the relative standard deviations of individual randomly selected bins to gain an impression of the statistical significance of these results. The mean relative standard deviations can be used globally for any bone age-, chronological age- or height-bin to calculate Zscores. This provides a good approximation and a considerable simplification over using a different standard deviation for each bin.

\section{Validation procedure}

This study goes beyond the publication that first presented the PBI by considering not only the relative variability of the indices under study but also their height dependence in children of equal chronological age or bone age [11]. These 


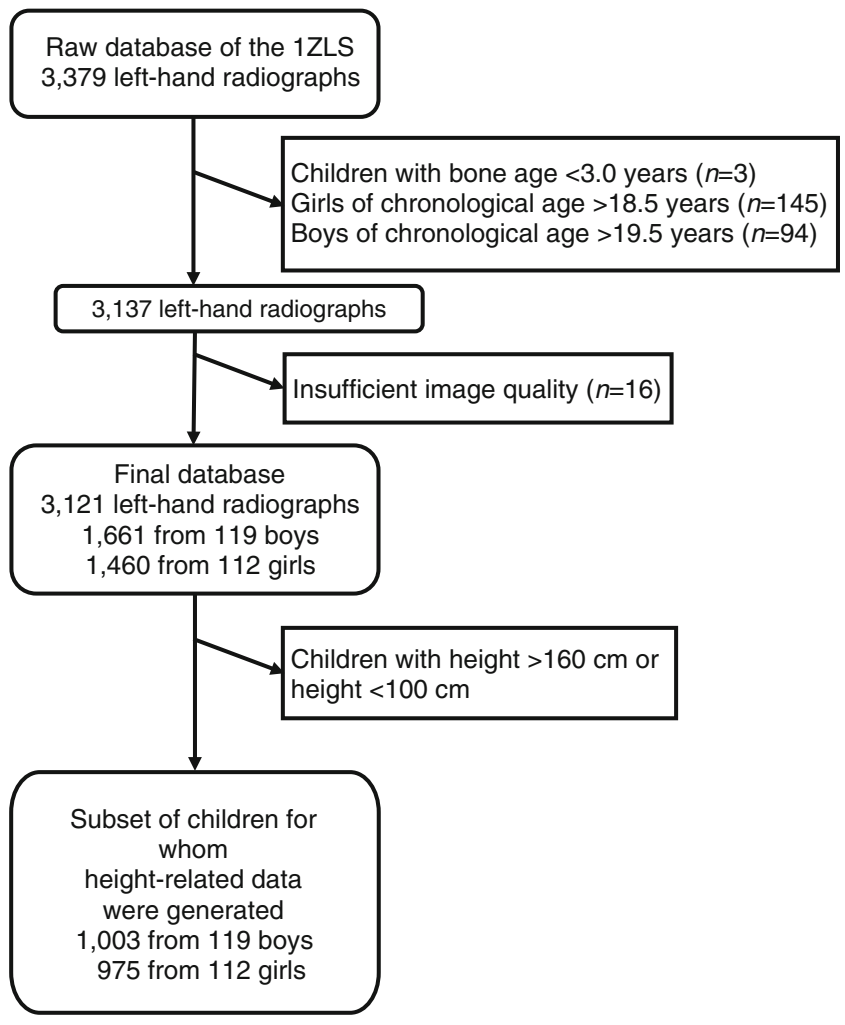

Fig. 1 Flowchart for inclusion in the study

two criteria are of a disparate nature and cannot be meaningfully linked by any statistical method. By considering them separately, we allowed the possibility of obtaining contradictory outcomes. Our study was thus exploratory, with collection of information being given priority over obtaining conclusive results.

\section{Results}

Figure 3 shows the curves of the five indices under study: BMD, RCA, ESI, PBI and BBRI versus bone age for boys and girls. The widely used MCI has also been included to illustrate its similarity to the RCA.

Figure 4 shows the correlations of BMD, RCA, ESI and PBI with BBRI, which is assumed to represent bone strength. The ellipses contain $90 \%$ of all data points.

Table 1 shows the relative variability of the indices to be lowest for PBI, followed by BMD, ESI, RCA and BBRI for the genders pooled. The ranking changed when boys and girls were considered separately. There were no significant differences among the first four indices.

Table 2 shows the height-related bias to be overall closest to zero in PBI, followed by RCA, BMD, ESI and BBRI in this order for the genders pooled, regardless of whether bone age- or chronological age-related values were considered. Both PBI and RCA showed significantly less height dependence than any of the other three indices $(p<0.05$ for each comparison) when both genders were pooled. The outcome changed when boys and girls were considered separately.

Table 3 gives reference data for PBI versus chronological age, bone age and 5 -cm height intervals.

\section{Discussion}

The need for an investigation of various radiogrammetrical metacarpal indices in use today is illustrated by Fig. 3. The curves of the two most widely used indices, BMD and MCI, are in particular strikingly different. An early attempt at defining a validation criterion was made by Thodberg [11], who suggested using relative variability. This was based on the assumption that when there is a choice between several parameters for describing a complex, poorly understood biological feature, the one with the lowest relative variability will indicate a feature that is important for the organism's survival, because nature is least willing to compromise and allow wide variation. Although the differences in relative variability here
Fig. 2 Illustration of the measurements of metacarpal cortical thickness $(\mathrm{T})$, width (W), medullary diameter (M) (left) and length (L) (right). The radiograph on the right also shows the regions in which the measurements were made
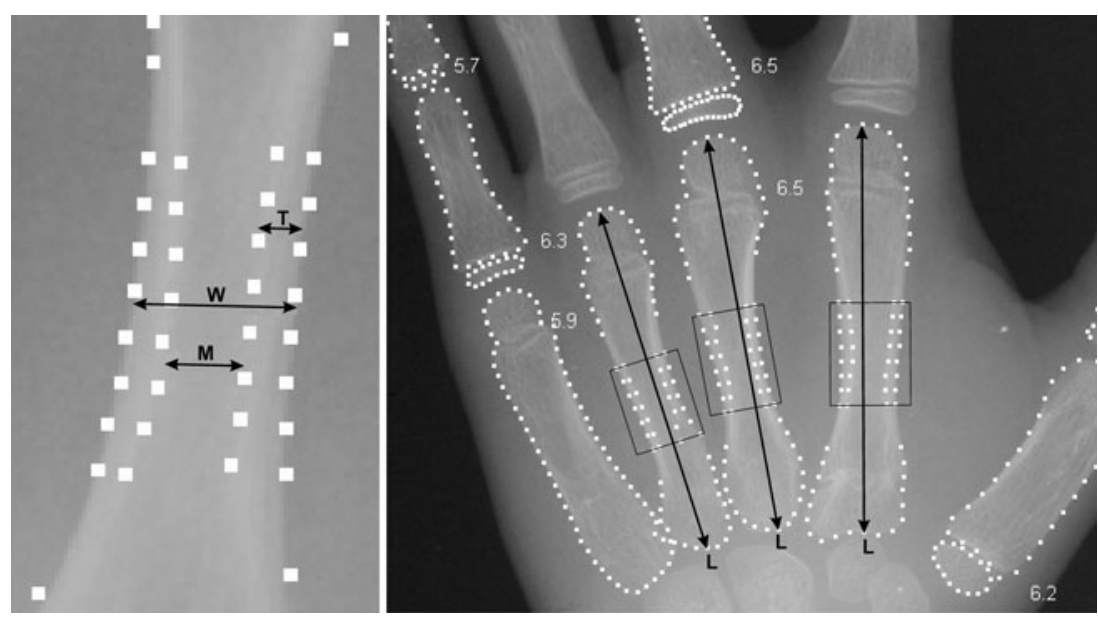

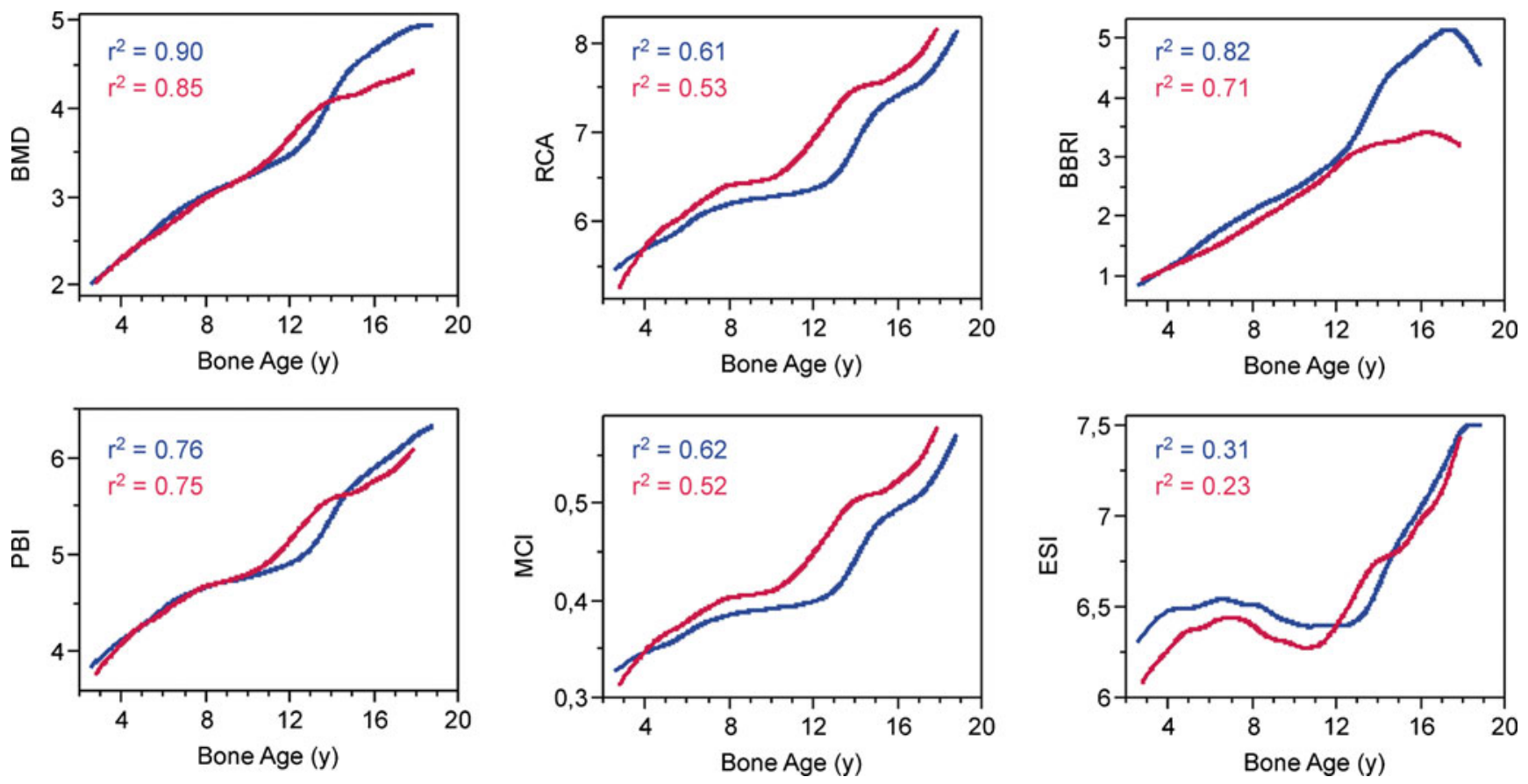

Fig. 3 Plots of bone mineral density (BMD), relative cortical area (RCA), Exton-Smith index (ESI), paediatric bone index (PBI) and bending breaking resistance index (BBRI) versus bone age for boys

are rather small, we believe that the criterion of minimal variability should in principle also apply to the field of bone physiology, especially considering the great economy with which organisms are known to make use of bone. (blue) and girls (red) depicted as splines (lambda $=10$ ). The coefficient of determination $r^{2}$ is given for each curve

The BBRI showed by far the greatest relative variability of the five indices under study (Table 1). Its 95\% CI per individual bin was well clear of those of any other index (not shown). Its large relative variability can also be seen
Fig. 4 Correlations of bone mineral density (BMD), relative cortical area (RCA), ExtonSmith index (ESI), paediatric bone index (PBI) and bending breaking resistance index (BBRI) as measurements of bone strength, expressed in terms of Pearson's $r$. The ellipses contain $90 \%$ of all data points
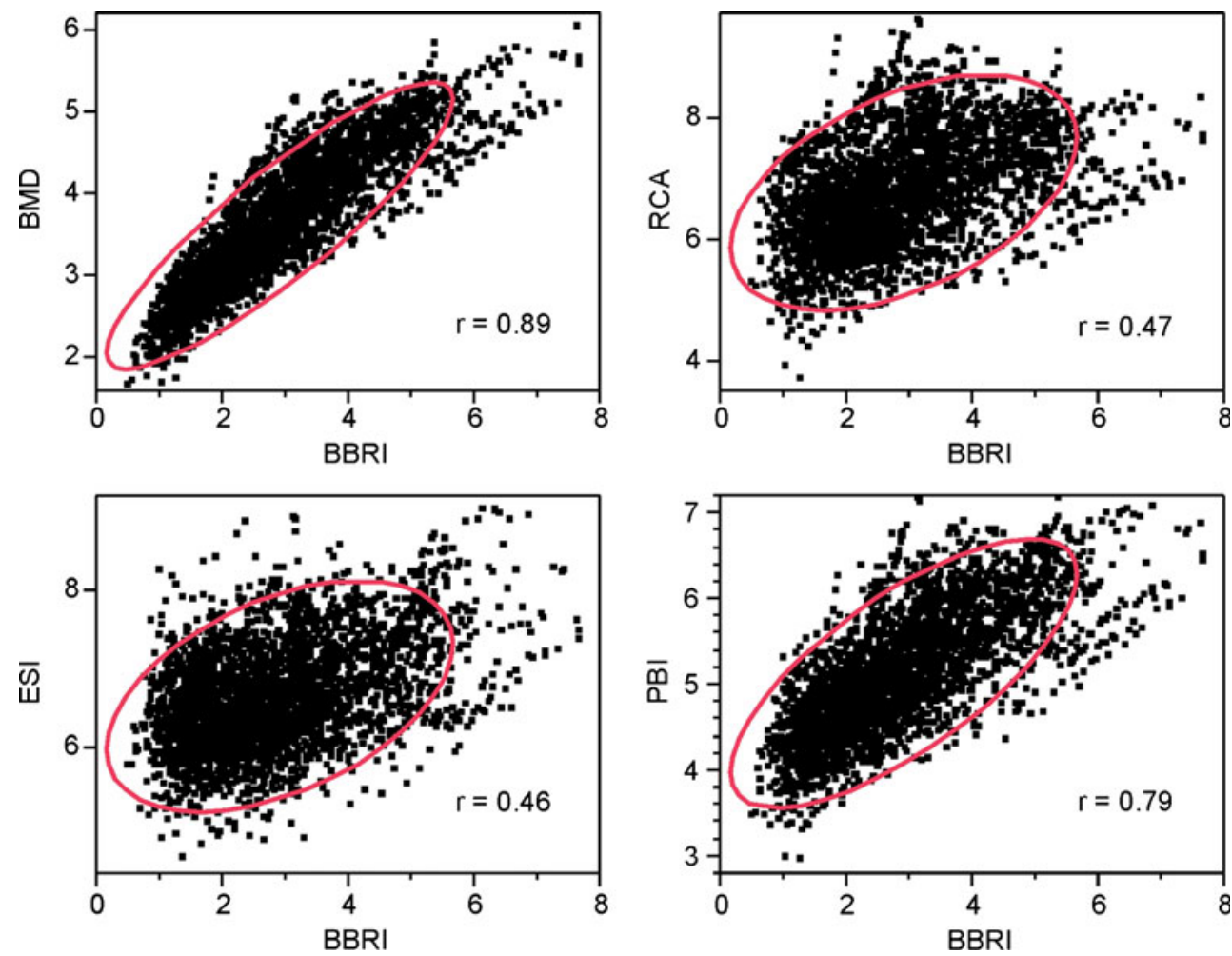
Table 1 Means and ranges of relative standard deviations (SD/mean percent) of bone mineral density (BMD), relative cortical area (RCA), Exton-Smith index (ESI), paediatric bone index (PBI) and bending breaking resistance index (BBRI), cortical thickness (T), bone width (W) and length (L), and medullary diameter (M), by gender from bone age 4 years to 17 years (girls) or 18 years (boys)

\begin{tabular}{lllllllllll}
\hline Group & Data & BMD & RCA & ESI & PBI & BBRI & T & W & L & M \\
\hline Boys & Mean \pm SD & $7.5 \pm 1.0$ & $8.1 \pm 1.2$ & $8.3 \pm 0.8$ & $7.1 \pm 0.9$ & $17.9 \pm 1.6$ & $9.6 \pm 1.0$ & $6.6 \pm 0.9$ & $5.4 \pm 0.4$ & $12.8 \pm 1.5$ \\
& Range & $6.5-10.2$ & $6.7-10.8$ & $6.9-10.3$ & $5.8-9.5$ & $15.8-21.1$ & $8.3-12.3$ & $5.6-8.9$ & $4.9-6.3$ & $10.9-16.0$ \\
Girls & Mean \pm SD & $7.6 \pm 0.6$ & $9.5 \pm 1.5$ & $8.5 \pm 0.5$ & $7.7 \pm 0.7$ & $17.5 \pm 1.4$ & $10.7 \pm 0.9$ & $7.0 \pm 0.6$ & $5.5 \pm 0.3$ & $15.8 \pm 2.2$ \\
& Range & $6.6-8.5$ & $7.5-12.5$ & $7.8-9.5$ & $6.7-9.3$ & $14.1-19.9$ & $9.2-12.1$ & $6.3-8.0$ & $5.0-6.2$ & $13.3-21.1$ \\
Total & Mean \pm SD & $7.5 \pm 0.8$ & $8.8 \pm 1.5$ & $8.4 \pm 0.7$ & $7.4 \pm 0.9$ & $17.7 \pm 1.5$ & $10.1 \pm 1.1$ & $6.8 \pm 0.8$ & $5.5 \pm 0.3$ & $14.3 \pm 2.4$ \\
& Range & $6.5-10.2$ & $6.7-12.5$ & $6.9-10.3$ & $5.8-9.5$ & $14.1-21.1$ & $8.3-12.3$ & $5.6-8.9$ & $4.9-6.3$ & $10.9-21.1$ \\
\hline
\end{tabular}

intuitively from its formula, which reflects the fact that the strength of a cylindrical tube grows increasingly rapidly with increasing width. To use the concept described above, the large relative variability of the BBRI in children of equal chronological or bone age is an indication that bone health is not accurately defined by bone strength alone. The error incurred by equating the BBRI with bone strength can be neglected here because of its large deviations compared to the other indices. Its validity as a rough measure of bone strength has been studied by Gatti et al. [45], who showed DXA-BBRI of the radius to be a better predictor of femoral neck fracture than DXA-BMD measured at the same site in women. The correlations of the other four indices with the BBRI, shown in Fig. 4, thus provide a rough impression of the degree to which each reflects bone strength.

Aside from the results for the BBRI, we were unable to demonstrate significant differences between the relative variability of the indices. It was lowest for PBI and BMD, which showed virtually no difference between them, followed by the ESI and RCA. To determine whether the differences are clinically relevant, it will be necessary to review paediatric fracture studies for which hand radiographs are available. This is of particular interest at chronological age of 6-8 years due to the high incidence of low-energy fractures in this age group [46]. Table 1 also gives the relative variability of the constituent parameters (T, W, L, M) which have been discussed in greater detail previously [40].

By contrast, our results on the height-dependence of the indices were more clear-cut (Table 2). Height-dependence was overall lowest for PBI and RCA, being slightly lower for PBI in terms of bone age and, by a smaller margin, slightly lower for RCA in terms of chronological age. When the results were pooled, the difference between these two indices was not statistically significant, but both PBI and RCA showed significantly lower height-dependence than any of the other three indices, regardless of whether chronological age or bone age-related data were considered ( $p<0.05$ for each single comparison). On the other hand, by gender the differences between PBI and RCA on the one hand and the other three indices on the other were smaller, especially in girls, where bone age-related height-dependence of BMD was even slightly smaller than that of PBI and RCA. The gender differences are related to the oestrogen-induced increase in $\mathrm{T}$, which is independent of height and muscle mass. These differences nearly disappeared at chronological age 6-11 years and were largest at 13-14 years.
Table 2 Height-related bias of bone mineral density (BMD), relative cortical area (RCA), Exton-Smith index (ESI), paediatric bone index (PBI) and bending breaking resistance index (BBRI) aggregated separately for boys and girls across bone ages 3-18 years (girls) or 319 years (boys) and expressed as bone age-related standard deviation scores (BASDS) per 2 height-BASDS and chronological age related standard deviation scores (CASDS) per 2 height-CASDS. (e.g. the first number, 0.53 , means that BMD will on average be 0.53 SDS higher in a child with a height for bone age of 2 SDS). $99.8 \%$ confidence intervals (CI) in square brackets

\begin{tabular}{|c|c|c|c|c|c|}
\hline Group & BMD & RCA & ESI & PBI & BBRI \\
\hline \multicolumn{6}{|l|}{ BASDS } \\
\hline Boys & $0.53[0.37 ; 0.68]$ & $0.02[-0.14 ; 0.18]$ & $-0.41[-0.56 ;-0.25]$ & $0.04[-0.12 ; 0.20]$ & $0.65[0.49,0.80]$ \\
\hline Girls & $0.27[0.11 ; 0.44]$ & $-0.43[-0.60 ;-0.27]$ & $-0.59[-0.75 ;-0.43]$ & $-0.30[-0.46 ;-0.13]$ & $0.89[0.74 ; 1.04]$ \\
\hline Total & $0.40[0.29 ; 0.52]$ & $-0.20[-0.32 ;-0.09]$ & $-0.50[-0.61 ;-0.38]$ & $-0.12[-0.24 ;-0.01]$ & $0.77[0.66-0.87]$ \\
\hline \multicolumn{6}{|c|}{ CASDS } \\
\hline Boys & $0.80[0.66 ; 0.94]$ & $0.11[-0.05 ; 0.26]$ & $-0.27[-0.43 ;-0.12]$ & $0.24[0.08 ; 0.40]$ & $0.92[0.78 ; 1.06]$ \\
\hline Girls & $0.49[0.34 ; 0.65]$ & $-0.25[-0.41 ;-0.09]$ & $-0.43[-0.59 ;-0.28]$ & $-0.07[-0.24 ; 0.09]$ & $0.99[0.85 ; 1.13]$ \\
\hline Total & $0.65[0.55 ; 0.76]$ & $-0.07[-0.18 ; 0.05]$ & $-0.35[-0.46 ;-0.24]$ & $0.09[-0.02 ; 0.20]$ & $0.95[0.85 ; 1.05]$ \\
\hline
\end{tabular}


Table 3 Reference values for paediatric bone index (PBI) by bone age, chronological age, height and gender. Means and standard deviations are given in $\mathrm{mm}^{0.33}$. The values for bone age 18-19 years in boys and 16-
18 years in girls are biased towards early maturers. Values outside the intended application range of BoneXpert ${ }^{\circledR}$ (bone-age $>17$ years in boys and $>15$ years in girls) should not be used for reference purposes

\begin{tabular}{|c|c|c|c|c|c|c|c|c|c|c|c|}
\hline \multicolumn{4}{|c|}{ PBI by bone age-bin (years) } & \multicolumn{4}{|c|}{ PBI by chronological age-bin (years) } & \multicolumn{4}{|c|}{ PBI by height-bin (5-cm intervals) } \\
\hline Bone age (years) & $N$ & Mean & SD & Chronological age (years) & $N$ & Mean & SD & Height (cm) & $N$ & Mean & $\mathrm{SD}$ \\
\hline \multicolumn{12}{|l|}{ Boys } \\
\hline 3 & 18 & 3.97 & 0.44 & 3 & 12 & 3.87 & 0.55 & $100.0-104.9$ & 20 & 4.20 & 0.37 \\
\hline 4 & 25 & 4.17 & 0.37 & 4 & 33 & 4.11 & 0.35 & $105.0-109.9$ & 36 & 4.21 & 0.39 \\
\hline 5 & 69 & 4.25 & 0.42 & 5 & 56 & 4.26 & 0.35 & $110.0-114.9$ & 49 & 4.32 & 0.36 \\
\hline 6 & 115 & 4.47 & 0.35 & 6 & 90 & 4.41 & 0.35 & $115.0-119.9$ & 72 & 4.43 & 0.35 \\
\hline 7 & 110 & 4.57 & 0.37 & 7 & 108 & 4.53 & 0.36 & $120.0-124.9$ & 92 & 4.56 & 0.34 \\
\hline 8 & 95 & 4.66 & 0.37 & 8 & 115 & 4.66 & 0.36 & $125.0-129.9$ & 90 & 4.60 & 0.36 \\
\hline 9 & 111 & 4.71 & 0.34 & 9 & 117 & 4.74 & 0.36 & $130.0-134.9$ & 101 & 4.70 & 0.37 \\
\hline 10 & 116 & 4.76 & 0.36 & 10 & 112 & 4.77 & 0.35 & $135.0-139.9$ & 117 & 4.78 & 0.40 \\
\hline 11 & 104 & 4.82 & 0.36 & 11 & 114 & 4.82 & 0.37 & $140.0-144.9$ & 118 & 4.82 & 0.36 \\
\hline 12 & 114 & 4.93 & 0.36 & 12 & 112 & 4.91 & 0.37 & $145.0-149.9$ & 104 & 4.90 & 0.36 \\
\hline 13 & 142 & 5.04 & 0.36 & 13 & 109 & 5.04 & 0.40 & $150.0-154.9$ & 97 & 4.91 & 0.35 \\
\hline 14 & 133 & 5.39 & 0.40 & 14 & 114 & 5.26 & 0.44 & $155.0-159.9$ & 79 & 5.09 & 0.41 \\
\hline 15 & 70 & 5.73 & 0.36 & 15 & 114 & 5.62 & 0.45 & & & & \\
\hline 16 & 81 & 5.88 & 0.42 & 16 & 114 & 5.86 & 0.43 & & & & \\
\hline 17 & 143 & 6.04 & 0.41 & 17 & 114 & 6.06 & 0.42 & & & & \\
\hline 18 & 189 & 6.23 & 0.38 & 18 & 115 & 6.15 & 0.41 & & & & \\
\hline 19 & 26 & 6.23 & 0.33 & 19 & 112 & 6.20 & 0.42 & & & & \\
\hline \multicolumn{12}{|l|}{ Girls } \\
\hline 3 & 20 & 3.87 & 0.44 & 3 & 13 & 3.71 & 0.36 & $100.0-104.9$ & 25 & 4.05 & 0.41 \\
\hline 4 & 45 & 4.05 & 0.39 & 4 & 32 & 4.02 & 0.37 & $105.0-109.9$ & 36 & 4.15 & 0.41 \\
\hline 5 & 52 & 4.28 & 0.37 & 5 & 53 & 4.22 & 0.38 & $110.0-114.9$ & 56 & 4.32 & 0.37 \\
\hline 6 & 80 & 4.42 & 0.43 & 6 & 90 & 4.37 & 0.39 & $115.0-119.9$ & 74 & 4.44 & 0.43 \\
\hline 7 & 123 & 4.53 & 0.39 & 7 & 98 & 4.56 & 0.39 & $120.0-124.9$ & 78 & 4.61 & 0.40 \\
\hline 8 & 127 & 4.69 & 0.37 & 8 & 111 & 4.66 & 0.38 & $125.0-129.9$ & 99 & 4.66 & 0.42 \\
\hline 9 & 101 & 4.72 & 0.40 & 9 & 107 & 4.72 & 0.40 & $130.0-134.9$ & 104 & 4.71 & 0.38 \\
\hline 10 & 120 & 4.79 & 0.36 & 10 & 106 & 4.79 & 0.39 & $135.0-139.9$ & 93 & 4.75 & 0.38 \\
\hline 11 & 104 & 4.95 & 0.41 & 11 & 103 & 4.86 & 0.42 & $140.0-144.9$ & 97 & 4.85 & 0.44 \\
\hline 12 & 100 & 5.13 & 0.40 & 12 & 104 & 5.05 & 0.49 & $145.0-149.9$ & 90 & 5.03 & 0.52 \\
\hline 13 & 73 & 5.37 & 0.40 & 13 & 106 & 5.30 & 0.50 & $150.0-154.9$ & 101 & 5.35 & 0.59 \\
\hline 14 & 87 & 5.58 & 0.39 & 14 & 106 & 5.53 & 0.46 & $155.0-159.9$ & 150 & 5.60 & 0.58 \\
\hline 15 & 88 & 5.62 & 0.41 & 15 & 111 & 5.66 & 0.46 & & & & \\
\hline 16 & 165 & 5.80 & 0.46 & 16 & 104 & 5.73 & 0.46 & & & & \\
\hline 17 & 151 & 5.85 & 0.43 & 17 & 105 & 5.79 & 0.46 & & & & \\
\hline 18 & 24 & 6.01 & 0.44 & 18 & 111 & 5.84 & 0.46 & & & & \\
\hline
\end{tabular}

The differences in height-dependence were large enough to be clinically relevant. In a study of 178 children with growth hormone deficiency, BMD CASDS improved from $-2.2 \pm 0.9$ to $-0.9 \pm 1.1$ after 4 years' growth hormone treatment, whereas in terms of PBI, CASDS the improvement was from $-1.6 \pm 1.0$ to $-0.6 \pm 1.1$ (publication under preparation). This shows that height-dependence is a potentially confounding factor in metacarpal indices and needs to be taken into account. The fact that growth disorders are the main indications for radiogrammetry in children makes it all the more relevant. The large height-related bias of BMD in healthy children suggests that height-dependence should be close to zero for an ideal index of bone health. On average a normal boy with height at the tenth percentile would have a BMD BASDS of -0.43 and a BMD CASDS of -0.64 (normal girl -0.22 BASDS and -0.40 CASDS). The idea 
that an ideal index of bone health should have minimal height-dependence has already been discussed [47]. To eliminate the inter-gender difference in height-dependence, one would have to formulate one index for boys and one for girls. Such refinements should perhaps be deferred until the relationship between bone health and height in children has been examined in fracture studies.

Figure 4 shows that in terms of its correlation with the BBRI, the PBI has an intermediate position between the BMD and the RCA, the two indices which came closest to it by our two assessment criteria. It is tempting to speculate that this is approximately the degree of correlation with bone strength that an ideal radiogrammetrical index of bone health should have.

On comparing our data with those of the Third Zurich Longitudinal Study, with birth dates from 1973 to 1991, we found very little change in the speed of skeletal maturation but quite large deviations in metacarpal measurements. The most conspicuous change was a decrease in $\mathrm{T}$. This would result in lower values for all the indices under study here. The causes underlying these very recent and very rapid changes in anthropometric measurements can hardly be identified with certainty. They may possibly be due to changes in lifestyle.

Aside from our two assessment criteria, the curves of Fig. 3 show further features that merit discussion. The decrease of BBRI versus bone age in both genders towards the end of the observation period is attributable to selection bias. The late maturers are underrepresented from bone age 17 years in boys and 15 years in girls due to our exclusion criteria. By keeping such a high cutoff, we ensured the validity of the data for the official bone age-range of BoneXpert ${ }^{\mathbb{B}}$ and of the Tanner-Whitehouse bone age system. This maturation effect is in itself interesting in that early maturers have a BBRI that is delayed for their bone age. Our outcomes remain unchanged if bone-age bins 18 and 19 in boys and 17 and 18 in girls are excluded to remove the bias towards early maturers in this range.

The reverse effect was seen in RCA, where the biasrelated decrease in $\mathrm{W}$ versus bone age was reflected by an upward turn at the end of its curve. This highlights a weak point of the RCA. With width squared in its denominator, it produces high scores for slender bones, the opposite of what one would expect from a bone health index. Similar reservations apply to the more widely used MCI.

One feature that was particularly well highlighted by ESI was the downward slope from bone age around 7-13 years in boys and $8-11$ years in girls. This reflects the dynamic changes in growth rate of $\mathrm{T}, \mathrm{W}$ and $\mathrm{L}$ during the prepubertal dip, with $\mathrm{T}$ first slowing down more than $\mathrm{W}$ and $\mathrm{L}$ and then surpassing them during puberty. This is discussed in detail elsewhere [40].

Taken together our findings strengthen the case for PBI as an improved metacarpal index for children. However, it still lacks an empirical basis. An important remaining task is to test it against clinical data from children with diseases that affect bone health. This would then also allow a direct comparison of PBI and indices derived from DXA, pQCT or US. One way of refining our approach would be to consider other correction factors besides height. To determine the dependence on muscle mass, which is the other major predictor of bone mass [31], one would have to turn to other databases.

With regards to fracture risk, the convenience of being able to use hand radiographs is only a real benefit if this gives information about bones that are more prone to fracture. An extensive meta-analysis by Marshall et al. [48] suggests that increased fracture risk is most often a global skeletal condition that can be diagnosed at different skeletal sites. A decrease in bone density (or mass) by one standard deviation at any site was shown to have a similar predictive value for fractures at all sites combined [48]. Ravn et al. [49] found high correlations between BMD of the phalanges, forearm and spine measured by radioabsorptiometry, suggesting a similar conjecture with regards to the metacarpals.

Aside from the question of fracture risk prediction, the PBI can be used as a quick, inexpensive and robust method of testing for normality when taking a radiograph for assessing skeletal maturity. Especially in children, using indices based on a simple hand radiograph circumvents the serious problem of keeping patients still during pQCT and DXA examinations. For example, we have been able to show that growth hormone treatment of children with growth hormone deficiency leads to a strong and significant increase in PBI within the first year of treatment as a result of subperiosteal bone deposition [50].

\section{Conclusion}

The paediatric bone index is less height dependent and may therefore be a better marker of pediatric bone health than area bone mineral density.

Acknowledgments We thank Novo Nordisk for lending us the Vidar scanner with which the 1ZLS radiographs were scanned (details of the scanning process are given in Reference [37]).

Open Access This article is distributed under the terms of the Creative Commons Attribution License which permits any use, distribution, and reproduction in any medium, provided the original author(s) and the source are credited.

\section{References}

1. Boot AM, Bouquet J, de Ridder MAJ et al (1997) Determinants of body composition measured by dual-energy X-ray absorptiometry in Dutch children and adolescents1. Am J Clin Nutr 66:232-238 
2. Boot AM, de Ridder MAJ, Pols HAP et al (1997) Bone mineral density in children and adolescents: relation to puberty, calcium intake, and physical activity. J Clin Endocrinol Metabol 82:57-62

3. Leonard MB, Shults J, Elliott DM et al (2004) Interpretation of whole body dual energy X-ray absorptiometry measures in children: comparison with peripheral quantitative computed tomography. Bone 34:1044-1052

4. Mentzel HJ, John U, Boettcher J et al (2005) Evaluation of bonemineral density by digital X-ray radiogrammetry (DXR) in pediatric renal transplant recipients. Pediatr Radiol 35:489-494

5. Mentzel HJ, Blume J, Boettcher J et al (2006) The potential of digital X-ray radiogrammetry (DXR) in the assessment of osteopenia in children with chronic inflammatory bowel disease. Pediatr Radiol 36:415-420

6. Neu CM, Manz F, Rauch F et al (2001) Bone densities and bone size at the distal radius in healthy children and adolescents: a study using peripheral quantitative computed tomography. Bone 28:227232

7. Schweizer R, Martin DD, Schwarze CP et al (2003) Cortical bone density is normal in prepubertal children with growth hormone (GH) deficiency, but initially decreases during GH replacement due to early bone remodeling. J Clin Endocrinol Metabol 88:52665272

8. van Rijn RR, Grootfaam DS, Lequin MH et al (2004) Digital radiogrammetry of the hand in a pediatric and adolescent Dutch Caucasian population: normative data and measurements in children with inflammatory bowel disease and juvenile chronic arthritis. Calcif Tissue Int 74:342-350

9. van Rijn RR, Boot A, Wittenberg R et al (2006) Direct X-ray radiogrammetry versus dual-energy $\mathrm{X}$-ray absorptiometry: assessment of bone density in children treated for acute lymphoblastic leukaemia and growth hormone deficiency. Pediatr Radiol 36:227-232

10. Adams JE (2010) Radiogrammetry and radiographic absorptiometry. Radiol Clin North Am 48:531-540

11. Thodberg HH, van Rijn RR, Tanaka T et al (2009) A paediatric bone index derived by automated radiogrammetry. Osteoporos Int 21:1391-400. doi:10.1007/s00198-009-1085-9

12. van Rijn RR, van Kuijk C (2009) Of small bones and big mistakes; bone densitometry in children revisited. Eur J Radiol 71:432-439

13. Hyldstrup L, Nielsen SP (2001) Metacarpal index by digital X-ray radiogrammetry normative reference values and comparison with dual X-ray absorptiometry. J Clin Densitom 4:299-306

14. Lee DC, Gilsanz V, Wren TAL (2007) Limitations of peripheral quantitative computed tomography metaphyseal bone density measurements. J Clin Endocrinol Metabol 92:42484253

15. Rosholm A, Hyldstrup L, Baeksgaard L et al (2001) Estimation of bone mineral density by digital $\mathrm{X}$-ray radiogrammetry: theoretical background and clinical testing. Osteoporos Int 12:961-969

16. Pfeil A, Haugeberg G, Hansch A et al (2011) Value of digital X ray radiogrammetry in the assessment of inflammatory bone loss in rheumatoid arthritis. Arthritis Care Res 63:666-674

17. Carrie Fässler AL, Bonjour JP (1995) Osteoporosis as a pediatric problem: pediatric nutrition. Pediatr Clin $\mathrm{N}$ Am 42:811-824

18. Kanis JA, Melton LJ, Christiansen C et al (1994) Perspective: the diagnosis of osteoporosis. J Bone Miner Res 2:1137-1141

19. Black DM, Palermo L, Sörensen T et al (2001) A normative reference database study for pronosco X-posure system. J Clin Densitom 4:5-12

20. Malich A, Freesmeyer MG, Mentzel HJ et al (2003) Normative values of bone parameters of children and adolescents using digital computer-assisted radiogrammetry (DXR). J Clin Densitom 6:103-111
21. Mentzel HJ, Mainz J, Schaefer M et al (2006) Peripheral bone status in children with asthma evaluated by digital X-ray radiogrammetry. Internet J Radiol 5:1

22. Mentzel HJ, Malich A, Kunze C et al (2007) Digitale Radiogrammetrie (DXR) - Referenzwerte der Knochenmineraldichte für Kinder und Jugendliche. Monatsschr Kinderheilkd 155:1622

23. van Rijn RR, van der Sluis I, Link T et al (2003) Bone densitometry in children: a critical appraisal. Eur Radiol 13:700-710

24. Ward KA, Cotton J, Adams JE (2003) A technical and clinical evaluation of digital X-ray radiogrammetry. Osteoporos Int 14:389-395

25. Garn SM (1970) The earlier gain and the later loss of cortical bone in nutritional perspective. Thomas, Springfield, IL, USA

26. Wishart JM, Horowitz M, Bochner M et al (1993) Relationships between metacarpal morphometry, forearm and vertebral bone density and fractures in postmenopausal women. $\mathrm{Br} \mathrm{J}$ Radiol $66: 435-440$

27. Tothill P (1989) Methods of bone mineral measurement. Phys Med Biol 34:543-572

28. Radetti G, D'Addato G, Gatti D et al (2006) Influence of two different GH dosage regimens on final height, bone geometry and bone strength in GH-deficient children. Eur J Radiol 154:479482

29. Schiessl H, Ferretti JL, Tysarczyk-Niemeyer G et al (1996) Noninvasive bone strength index as analyzed by peripheral quantitative computed tomography (pQCT). In Schoenau E. (ed) Paediatric osteology: New developments in diagnostics and therapy. Elsevier Science, Amsterdam, pp 141-146

30. Specker BL, Schoenau E (2005) Quantitative bone analysis in children: current methods and recommendations. J Pediatr 146:726731

31. Schoenau E (2004) The peak bone mass concept: is it still relevant? Pediatr Nephrol 19:825-831

32. Högler W, Shaw N (2009) Childhood growth hormone deficiency, bone density, structures and fractures: scrutinizing the evidence. Clin Endocrinol 72:281-289

33. Exton-Smith AN, Millard PH, Payne PR et al (1969) Pattern of development and loss of bone with age. Lancet 7631:1154 1157

34. Gryfe CI, Exton-Smith AN, Payne PR et al (1971) Pattern of development of bone in childhood and adolescence. Lancet 7698:523-526

35. Gasser T, Sheehy A, Largo RH (2001) Statistical characterization of the pubertal growth spurt. Ann Hum Biol 28:395-402

36. Prader A, Largo RH, Molinari L et al (1989) Physical growth of Swiss children from birth to 20 years of age. First Zurich Longitudinal study of growth and development. Helv Paediatr Acta Suppl 52:1-125

37. Martin DD, Neuhof J, Jenni OG et al (2010) Automatic determination of left- and right-hand bone age in the First Zurich Longitudinal study. Horm Res Paediatr 74:50-55. doi:10.1159/000313369

38. Thodberg HH (2009) An automated method for determination of bone age. J Clin Endocrinol Metabol 94:2239-2244

39. Thodberg HH, Jenni OG, Caflisch J et al (2009) Prediction of adult height based on automated determination of bone age. J Clin Endocrinol Metabol 94:4868-4874

40. Martin DD, Heckmann C, Jenni OG et al (2009) Metacarpal thickness, width, length and medullary diameter in children reference curves from the First Zürich Longitudinal study. Osteoporos Int 22:1525-1536. doi:10.1007/s00198-010-13899

41. Thodberg HH, Kreiborg S, Juul A et al (2009) The BoneXpert method for automated determination of skeletal maturity. IEEE Trans Med Imaging 28:52-66 
42. van Rijn RR, Lequin MH, Thodberg HH (2009) Automatic determination of Greulich and Pyle bone age in healthy Dutch children. Pediatr Radiol 39:591-597

43. Martin DD, Deusch D, Schweizer R et al (2009) Clinical application of automated Greulich-Pyle bone age determination in children with short stature. Pediatr Radiol 39:598-607

44. Martin DD, Sato K, Sato M et al (2010) Validation of a new method for automated determination of bone age in Japanese children. Horm Res Paediatr 73:398-404

45. Gatti D, Sartori E, Braga V et al (2001) Radial bending breaking resistance derived by densitometric evaluation predicts femoral neck fracture. Osteoporos Int 12:864-869

46. Tiderius CJ, Landin L, Diippe H (1999) Decreasing incidence of fractures in children: an epidemiological analysis of 1,673 fractures in Malmö, Sweden, 1993-1994. Acta Orthop 70:622-626
47. Faulkner RA, Davison KS, Bailey DA et al (2006) Size-corrected BMD decreases during peak linear growth: implications for fracture incidence during adolescence. J Bone Miner Res 21:1864 1870

48. Marshall D, Johnell O, Wedel H (1996) Meta-analysis of how well measures of bone mineral density predict occurrence of osteoporotic fractures. Br Med J 312:1254-1259

49. Ravn P, Overgaard K, Huang C et al (1996) Comparison of bone densitometry of the phalanges, distal forearm and axial skeleton in early postmenopausal women participating in the EPIC study. Osteoporos Int 6:308-313

50. Martin DD, Heckmann C, Walter C et al (2012) Differentiation of growth hormone effects on metacarpal bone and bone age in children with growth hormone deficiency. Osteoporos Int (submitted) 